\title{
Risk factors influencing the outcomes in infants with epilepsy
}

\author{
Setyo Handryastuti, Irawan Mangunatmadja
}

\begin{abstract}
Background Epilepsy in young children should always be considered as a symptom of an underlying brain disease. Parents and caregivers often asked whether the seizures can be controlled and whether the epilepsy will affect the child development.

Objective To find out risk factors influencing the outcomes in infants with epilepsy.

Methods This was a retrospective study on infants aged 1 month until 12 months with recurrent epileptic seizures. We looked for the risk factors as sex, types of medication, age at onset of seizure, epilepsy syndrome, etiology of epilepsy, history of neonatal seizure, first EEG features, and type of seizure for the last 6 month-period. The outcomes evaluated were controlled seizure and developmental status.

Results Hundred forty infants with epilepsy were reviewed, consisted of 84 (60\%) infants with symptomatic epilepsy, and 56 (40\%) infants categorized as idiopathic. Forty-six (33\%) infants had controlled seizure, while 94 (67\%) infants had uncontrolled seizure. Abnormal developmental status was found in 75 infants (54\%). Abnormal developmental status was more found in infants with polytherapy, age at onset of 1-4 months, symptomatic epilepsy, positive remote symptomatic, history of neonatal seizure, abnormality of first EEG, and uncontrolled seizure. Uncontrolled seizure of epilepsy was more found in infants with polytherapy, early age at onset (1-4 month old), symptomatic epilepsy, positive remote symptomatic, history of neonatal seizure, and abnormality of first EEG.

Conclusion Our data indicate that classifying syndrome of epilepsy through diagnostic screening and age of onset are important to determine the outcomes. [Paediatr Indones 2007;47:202-206].
\end{abstract}

Keywords: recurrent epileptic seizure, symptomatic epilepsy, risk factors
$\mathrm{E}$ pilepsy in young children should always be considered as a symptom of an underlying brain disease, and therefore needs diagnostic screening, including neurogenetic, neurometabolic, and neuroradiologic testing. Seizures are common in infancy and reflect a variety of underlying causes. The most frequent seizure in that age group is febrile seizure, which is usually benign and has no risk on the further child's development. ${ }^{1-3}$ On the other hand, infantile spasm in infancy indicates an age-specific catastrophic epilepsy syndrome, with major negative implications for the development of the child. 4,5 The two most important questions regarding seizures usually asked by parents and caregivers are whether the seizures can be controlled and whether the epilepsy will affect the child development. We performed a retrospective study to find out risk factors for outcomes in infants with epilepsy.

From The Department of Child Health, Medical School, University of Indonesia, Jakarta, Indonesia.

Reprint Requests to: Setyo Handryastuti, MD, Department of Child Health, Medical School, University of Indonesia, Cipto Mangunkusumo Hospital, Jl. Salemba 6, Jakarta 10430, Indonesia. Tel. 62-21-3907742, Fax. 62-21-3907743. 
Setyo Handryastuti et al: Risk factors influencing the outcomes in infants with epilepsy

\section{Methods}

We collected medical records of all children aged between 1 month - 12 months with recurrent epileptic seizures, admitted to our hospital for diagnosis and treatment during January 2000 . October 2005. Infants with febrile seizures or infantile spasm were excluded. The diagnosis was based on history, clinical manifestations, physical examination, standard electroencephalogram, and head CT-scan. All patients received monotherapy with valproic acid or phenobarbital as the first line treatment; in the case that the seizures could not be controlled, the drug was changed or added. We traced back the possible risk factors for outcomes, i.e., type of therapy (monotherapy or polytherapy), age at onset (1-4 months, 5-8 months, or 9-12 months), type of epilepsy (localized or generalized, symptomatic or idiopathic), remote symptomatic, history of neonatal seizures, and abnormality of first EEG features. Remote symptomatic was defined when the child had either preexisting neurological abnormalities, a history of brain insult, or disorders associated with an increased risk of epilepsy that were presumed to be etiologically related to the infant's epilepsy. ${ }^{6}$ The outcomes, i.e., controlled epilepsy and developmental status were determined. Controlled epilepsy was defined as the child had no seizure during the last 6 month-period, while uncontrolled epilepsy was if there were still epileptic seizures. Developmental status was assessed by specific history taking and clinical examination. We used Bailey Infants Neurodevelopmental Scale (BINS) for screening combined with neurological examination such as physiological reflexes, pathological reflexes, tone, and neurodevelopmental examination. Developmental status was considered abnormal when developmental milestones were not achieved at an expected age, or when language and communication developments were delayed. All infants in this study visited regularly every 1-3 months to our hospital, so the infant development and respond to therapy were well-recorded.

The study subjects were also categorized into the idiopathic or symptomatic group. Infants in symptomatic group had a definite cause for the epileptic seizures or had developmental delay without a definite cause or etiology, which was called cryptogenic. In the idiopathic group, infants had no cause for the epilepsy other than a possible hereditary predisposition. ${ }^{7}$ Data were analyzed with chi-square test, relative risk (RR) and 95\% confidence intervals (CI) were supplied.

\section{Results}

A total of 140 consecutive infants ( 74 girls and 66 boys) were included in this study. The observation period ranged from 6 months to 55 months, with the median of 16 months. Eighty-four infants (60\%) were classified in the symptomatic group and $56(40 \%)$ in the idiopathic group. Developmental abnormalities were found in 75 infants (53\%), 72 infants in symptomatic group and 3 infants in idiopathic group. Sixty-five infants had normal development (47\%), most of them (53 infants) were in idiopathic group and 12 infants in symptomatic group. Uncontrolled seizures were found in 46 infants (32\%), 44 infants in symptomatic group, 2 infants in idiopathic group. Seizures were controlled in 94 infants (68\%), 40 infants in symptomatic group, and 54 infants in idiopathic group. Compared to those in idiopathic group, infants in symptomatic group had significantly higher proportion of having polytherapy, earlier age of onset, positive remote symptomatic, abnormal development, positive history of neonatal seizures, abnormal EEG features, and uncontrolled seizures. SeeTable 1 .

During the observation, the number of infants who had treatment switch was recorded. A treatment switch indicated that another medication was prescribed, as add-on or as an alternative monotherapy. The reason for a treatment switch was related to possible failure of initial treatment. In a way, it reflected how difficult to control the epilepsy.

Developmental abnormalities were more commonly found in of infants with polytherapy, early age at onset (1-4 months), symptomatic epilepsy, positive remote symptomatic, history of neonatal seizures, abnormality of the first EEG feature, and uncontrolled seizures (Table 2). The occurrence of abnormal development was not significantly different between infants with onset of seizure at 5-8 months old compared to them with onset of 9-12 months old.

Uncontrolled seizure was more commonly seen in infants with polytherapy, early age of onset (1-4 months), symptomatic epilepsy, positive remote 
Setyo Handryastuti et al: Risk factors influencing the outcomes in infants with epilepsy

Table 1. Characteristics of the study subjects

\begin{tabular}{|c|c|c|c|}
\hline Characteristics & $\begin{array}{c}\text { Symptomatic } \\
\text { group } \\
(n=84)\end{array}$ & $\begin{array}{l}\text { Idiopathic } \\
\text { group } \\
(\mathrm{n}=56)\end{array}$ & $\mathrm{P}$ \\
\hline \multicolumn{4}{|l|}{ Age at onset } \\
\hline 1- 4 months & $38(27 \%)$ & $7(5 \%)$ & \\
\hline 5- 8 months & $32(23 \%)$ & $35(25 \%)$ & \\
\hline 9-12 months & $14(10 \%)$ & $14(10 \%)$ & $<0.001$ \\
\hline \multicolumn{4}{|l|}{ Sex } \\
\hline Girl & $41(29 \%)$ & $33(24 \%)$ & \\
\hline Boy & $43(31 \%)$ & $23(16 \%)$ & $>0.05$ \\
\hline \multicolumn{4}{|c|}{ History of neonatal seizure } \\
\hline Positive & $13(9 \%)$ & $2(1 \%)$ & \\
\hline Negative & $71(51 \%)$ & $54(39 \%)$ & $<0.05$ \\
\hline \multicolumn{4}{|c|}{$\begin{array}{l}\text { Seizures for the last } 6 \text { month- } \\
\text { period }\end{array}$} \\
\hline Uncontrolled & $44(31 \%)$ & $2(1 \%)$ & \\
\hline Controlled & $40(29 \%)$ & $54(39 \%)$ & $<0.001$ \\
\hline \multicolumn{4}{|l|}{ Epilepsy syndrome } \\
\hline $\begin{array}{l}\text { Localized } \\
\text { Lolits }\end{array}$ & $13(9 \%)$ & 7 (5\%) & \\
\hline Generalized & $71(51 \%)$ & $49(35 \%)$ & $>0.05$ \\
\hline \multicolumn{4}{|c|}{ Remote symptomatic } \\
\hline Positive & $58(41 \%)$ & $1(1 \%)$ & \\
\hline Negative & $26(19 \%)$ & $55(39 \%)$ & $<0.001$ \\
\hline \multicolumn{4}{|l|}{ First EEG feature } \\
\hline Abnormal & $62(44 \%)$ & $9(6 \%)$ & \\
\hline Normal & $22(16 \%)$ & $47(34 \%)$ & $<0.001$ \\
\hline \multicolumn{4}{|l|}{ Type of therapy } \\
\hline Polytherapy & $33(24 \%)$ & $1(1 \%)$ & \\
\hline Monotherapy & $51(36 \%)$ & $55(39 \%)$ & $<0.001$ \\
\hline \multicolumn{4}{|c|}{ Developmental status } \\
\hline Abnormal & $72(51 \%)$ & $3(2 \%)$ & \\
\hline Normal & $12(9 \%)$ & $53(38 \%)$ & $<0.001$ \\
\hline
\end{tabular}

Table 2. Distribution of risk factors for developmental outcomes

\begin{tabular}{|c|c|c|c|c|c|}
\hline Factors & $\begin{array}{c}\text { Developmer } \\
\text { Abnormal } \\
(n=75)\end{array}$ & $\begin{array}{c}\text { ntal stat } \\
\text { Normal } \\
(\mathrm{n}=65)\end{array}$ & $\begin{array}{l}\text { tus } \\
\text { I RR }\end{array}$ & $95 \% \mathrm{Cl}$ & $\mathrm{P}$ \\
\hline \multicolumn{6}{|l|}{ Sex } \\
\hline Girls & 37 & 37 & & & \\
\hline Boys & 38 & 28 & 0.87 & $0.64-1.18$ & $>0.05$ \\
\hline \multicolumn{6}{|l|}{ Type of therapy } \\
\hline Polytherapy & 32 & 2 & 2.32 & $1.81-2.9$ & $<0.001$ \\
\hline Monotherapy & 43 & 63 & & & \\
\hline \multicolumn{6}{|c|}{ Age at seizure onset } \\
\hline 1-4 months & 34 & 11 & 1.51 & $1.00-2.26$ & $<0.05$ \\
\hline 5-8 months & 27 & 40 & 0.80 & $0.5-1.29$ & $>0.05$ \\
\hline 9-12 months & 14 & 14 & & & \\
\hline \multicolumn{6}{|c|}{ Epilepsy syndrome } \\
\hline Symptomatic & 72 & 12 & 16 & $5.30-48.27$ & $<0.001$ \\
\hline Idiopathic & 3 & 53 & & & \\
\hline Localized & 9 & 11 & & & \\
\hline Generalized & 66 & 54 & 0.81 & $0.49-1.36$ & $>0.05$ \\
\hline \multicolumn{6}{|c|}{ Remote symptomatic } \\
\hline Yes & 56 & 3 & 4 & $2.71-6.02$ & $<0.001$ \\
\hline No & 19 & 62 & & & \\
\hline \multicolumn{6}{|c|}{$\begin{array}{l}\text { History of neonatal } \\
\text { seizures }\end{array}$} \\
\hline Yes & 12 & 3 & 1.58 & $1.16-2.15$ & $<0.05$ \\
\hline No & 63 & 62 & & & \\
\hline \multicolumn{6}{|l|}{ First EEG } \\
\hline Abnormal & 55 & 16 & 2.67 & $1.81-3.94$ & $<0.001$ \\
\hline Normal & 20 & 49 & & & \\
\hline \multicolumn{6}{|c|}{$\begin{array}{l}\text { Seizure for the last } \\
6 \text { month-period }\end{array}$} \\
\hline Uncontrolled & 41 & 5 & 2.46 & $1.85-3.28$ & $<0.001$ \\
\hline Controlled & 34 & 60 & & & \\
\hline
\end{tabular}

Table 3. Distribution of risk factors for controlled seizures

\begin{tabular}{|c|c|c|c|c|c|}
\hline \multirow[b]{2}{*}{ Factors } & \multicolumn{2}{|c|}{ Controlled seizures } & \multirow[b]{2}{*}{$\mathrm{RR}$} & \multirow[b]{2}{*}{$95 \% \mathrm{Cl}$} & \multirow[b]{2}{*}{$\mathrm{P}$} \\
\hline & $\begin{array}{c}\text { Uncontrolled } \\
\text { (46) }\end{array}$ & $\begin{array}{c}\text { Controlled } \\
(94)\end{array}$ & & & \\
\hline \multicolumn{6}{|l|}{ Sex } \\
\hline Girl & 26 & 48 & 1.16 & $0.72 ; 1.87$ & $>0.05$ \\
\hline Boy & 20 & 46 & & & \\
\hline \multicolumn{6}{|l|}{ Therapy } \\
\hline Polytherapy & 27 & 7 & 4.43 & $2.85 ; 6.89$ & $<0.001$ \\
\hline Monotherapy & 19 & 87 & & & \\
\hline \multicolumn{6}{|l|}{$\begin{array}{l}\text { Age at seizure } \\
\text { onset }\end{array}$} \\
\hline 1-4 months & 24 & 21 & 2.98 & $1.29 ; 6.91$ & $<0.05$ \\
\hline $5-8$ months & 17 & 50 & 1.42 & $0.58 ; 3.47$ & $>0.05$ \\
\hline 9-12 months & 5 & 23 & & & \\
\hline \multicolumn{6}{|l|}{$\begin{array}{l}\text { Epilepsy } \\
\text { syndrome }\end{array}$} \\
\hline Symptomatic & 44 & 40 & 14.67 & $3.70 ; 58.07$ & $7<0.001$ \\
\hline Idiopathic & 2 & 54 & & & \\
\hline Localized & 3 & 17 & 0.42 & $0.14 ; 1.22$ & $>0.05$ \\
\hline Generalized & 43 & 77 & & & \\
\hline \multicolumn{6}{|l|}{$\begin{array}{l}\text { Remote } \\
\text { symptomatic }\end{array}$} \\
\hline Yes & 32 & 27 & 3.14 & $1.84 ; 5.33$ & $<0.001$ \\
\hline No & 14 & 67 & & & \\
\hline \multicolumn{6}{|c|}{ Neonatal seizures } \\
\hline Yes & 9 & 6 & 2.03 & $1.23 ; 3.32$ & $<0.05$ \\
\hline No & 37 & 88 & & & \\
\hline \multicolumn{6}{|l|}{ First EEG } \\
\hline Abnormal & 35 & 36 & 3.09 & $1.71 ; 5.58$ & $<0.001$ \\
\hline Normal & 11 & 58 & & & \\
\hline
\end{tabular}

symptomatic, history of neonatal seizures, and abnormality of the first EEG feature.

\section{Discussion}

Although the number of subjects in this study was rather small and the observation period was short to draw any definite conclusions, this study provides some important clinical guidelines for the pediatric epilepsy clinic. Clinical parameters that are readily available during the clinical monitoring of these young children with epilepsy were used. Infants less than 12 months of age with epileptic seizures, which neither febrile seizures nor infantile spasms, are real diagnostic challenges for neuropediatricians.

In this study, a definite cause of the epilepsy was found in 42\% (59/140) infants. This proportion maybe higher if we performed other neurodiagnostic screening, including a magnetic resonance imaging study, genetic studies, and a metabolic evaluation. We did not perform such examinations because of the cost. Seventy five percent of the patients $(106 / 140)$ 
received monotherapy, most of them $(63 / 106)$ had normal developmental and 87 patients in this group got control seizure. It was stated in the literature that more seizures and more anti epileptic drugs (AED) that we used can disturb the brain development. ${ }^{6,8}$ So it is understood that less AED and less seizure will not influence developmental outcome.

Developmental abnormalities were more commonly found in infants with symptomatic epilepsy, earlier age of onset (1-4 months), history of neonatal seizures, positive remote symptomatic, abnormality of the first EEG, having polytherapy, and uncontrolled seizures. The first five factors reflected the underlying brain diseases. Brain in children in the early age is vulnerable against seizures. The developing brain is more affected rather than the mature brain. These factors influenced the developmental outcomes.

In children with symptomatic epilepsy (84/140), most had abnormal EEG feature (62/84), abnormal developmental status (72/84) and had uncontrolled seizures (44/84). Underlying brain diseases described by positive remote symptomatic and abnormality of first EEG might be the cause or focus for epileptic seizures. We must consider a more aggressive treatment if we find symptomatic epilepsy especially in infant to reduce the seizures.

The developmental abnormalities are also influenced by recurrent or uncontrolled seizures. The epileptic process itself, perhaps in combination with the number of seizures, can be held responsible for the developmental delay. ${ }^{8}$

Uncontrolled seizure means that seizure could not be terminated by monotherapy, so add-on therapy or switching drugs must be done to control the seizure. Uncontrolled seizures were more commonly found in infants having polytherapy, early age of onset (1-4 months), symptomatic epilepsy, positive remote symptomatic, history of neonatal seizures and abnormality of the first EEG group. The underlying brain disease maybe was the cause of uncontrolled seizures which did not respond to the therapy.

Our results were different from larger studies reported in the literature. In a study by Cavazzutti et $a l^{9}, 482$ children were monitored for more than 5 years. In their subgroup of children without febrile seizures, status epilepticus, or infantile spasms, only 24\% developed normally. This suggests a possible long-term negative developmental effect of seizures in the first year of life. Similar findings have been reported in the older studies of Chevrie and Aicardi. ${ }^{10}$ In their large cohort of 313 children, poor prognosis was found even in non-febrile group of infants with seizures. Both studies further illustrated that age of onset of $>6$ months old, generalized seizures, and normal EEG, were associated with better, but still poor outcomes. Battaglia et al ${ }^{11}$ demonstrated in their study of 150 children that partial epilepsies were associated with poor outcomes. They also drew attention to the fact that persistence of seizures was a negative factor for developmental outcome, as was also observed in this study.

In conclusion, our data together with the existing data in the literature indicate that classifying epilepsy through diagnostic screening in an infant presenting with epileptic seizures is necessary. The finding of an underlying cause is a determinant factor for outcomes, especially for developmental level and responds to therapy. Most of infants with epilepsy have seizure free with monotherapy, but seizure control is more difficult to achieve in symptomatic cases.

\section{References}

1. Knudsen FU. Febrile seizures: treatment and prognosis. Epilepsia 2000;41:2-9.

2. Verity CM, Greenwood R, Golding J. Long-term intellectual and behavioral outcomes of children with febrile convulsions. N Eng J Med 1998;338:1723-8.

3. Vanderlinden L, Lagae LG. Clinical predictors for outcome in infants with epilepsy. Pediatr Neurol 2003;31:52-5.

4. Shields WD. Catastrophic epilepsy in childhood. Epilepsia 2000;41:S2-6.

5. Dulac OJ, Chiron C. Malignant epileptic encephalopaties in children. Bailiries Clin Neurol 1996;5:765-81.

6. Kwong KL, Sung WY, Wong SN, So KT. Early predictors of medical intractability in childhood epilepsy. Pediatr Neurol 2003;29:46-52.

7. Engel J Jr. A proposed diagnostic scheme for people with epileptic seizures and with epilepsy: report of the ILAE Task Force on Classification and Terminology. Epilepsia 2001;42:796-803.

8. Lado FA, Sankar R, Lowenstein D, Moshe SL. Agedependent consequences of seizures: Relationship to seizure frequency, brain damage, and circulatory reorganization. Ment Retard Dev Disabil Res Rev 2000;6:242-52.

Paediatr Indones, Vol. 47, No. 5, September 2007 • 205 
Setyo Handryastuti et al: Risk factors influencing the outcomes in infants with epilepsy

9. Cavazzutti GB, Ferrari P, Lalla M. follow-up study of 482 cases with convulsive disorders in the first year of life: Neurological and cognitive outcome. Eur J Pediatr Neurol 1999;26:425-37.

10. Chevrie JJ, Aicardi J. Convulsive disorders in the first year of life: Neurological and mental outcome and mortality.
Epilepsia 1978;19:67-74.

11. Battaglia D, Rando T, Deodato F, Bruccini G, Baglio G, Frisone MF, et al. Epileptic disorders with onset the first year of life: Neurological and cognitive outcome. Eur J Paeditr Neurol 1999;3:95-103. 